\title{
Thoughts on perfecting leisure and fitness service in Chinese urban communities
}

\author{
Songbo He \\ School of Physical Education, Beihua University, Jilin Jilin, 132021,China
}

Keywords: City, Community, leisure and fitness, Service, Thoughts.

\begin{abstract}
With the progress of the society and the gradual establishment of urban integrated structure, society as the important symbol of city development has attract attention from the whole society. Whether the community develops well has become the key indicator in the regional development process. Government should not only use social influence to satisfy people's mental demands but also should focus on adding and organizing leisure and fitness activities so as to improve people's physical quality. Developing community fitness service is an essential method. This article makes a brief analysis on the connotation of city community leisure and fitness, and focuses on explaining the functions, types, and features of city community leisure and fitness service and makes an in-depth exploration on the extended mechanism of service through combining the relationship mechanism of city community leisure fitness service facilities with the purpose of providing effective management suggestions for social management staffs.
\end{abstract}

\section{Introduction}

The course of the reform and opening-up policy has promoted rapid development of Chinese socialist modernization. The establishment of communities has changed people's life styles. People are not only limited in independent spaces but stepping into community service items. The setting of community fitness facilities, square dance and community sports activities are constructing a scientific and civilized leisure life style which can not only satisfy modern people's life demands but can also optimize the construction of harmonious society.

\section{The connotation of city community leisure fitness service}

In recent years, people are paying attention to social service projects. Particularly Chinese sports management staffs and social relation scholars have made profound analysis on community practical activities including the explanation on the connotation of city community leisure fitness service projects. They standardize the region for people to live together as the community and regard the natural environment and sports facilities within the region as the basic material foundation. Use multiple methods to satisfy the sports demands from the whole community members so as to improve the physical and psychological health of people in the community. Consolidate and develop the emotional exchange between members within the community through various activities. Use the community leisure fitness to realize the natural and harmonious development. The service projects based on this can be seen as the city community leisure fitness service [1].

\section{Functions of city community leisure fitness service}

\section{Socialization function}

Establishing city community leisure fitness mechanism is establish projects based on the life characteristics of modern people. In nowadays when globalization is developing and widely spreading, the survival ways of people in the society has decided the life quality. They depend more on the society so that they cannot independently exist without the society. People are looking for roads in the social civilization development as well as their own life styles with the precondition that they are qualified with different capabilities to integrate into the society. Social economic 
development has promoted the rapid progress of economy but also brought about different social situations. With the society gets highly urbanization, people's labor condition has changed also. This has led to a large-scale reduction of the social relations so that people are hiding in independent spaces producing serious communication shortage due to the difference of labor distribution and professional social functions. The so-called Circle of Friends is a fixed social scope. People's communication path with the outside has gradually transformed to computer platform with few and few chances for face-face exchanges so that there comes into being a vicious circle of social communication. Community activity is the best path to get neighbors closer. Due to the publicity of activity sites, the social interaction frequency has been improved so that the socialized upgrade has been realized. In addition, during city community leisure fitness, people can communicate equally. This has formed harmonious relations. Besides, the completeness of city community leisure fitness service system and structure has directly decided the degree of urban socialization and it can directly show the basic framework of city development as well.

\section{Individualization function}

Promoting city community leisure fitness service can not only improve social group's comprehensive qualities but can also scientifically promote individuals' overall development. Firstly, city community leisure fitness activities can effectively maintain individual physical and mental health. The speed of modern social development is quickening and peoples' life pace is speeding up. They are facing up to larger and larger social pressure and competition so that they need an approach to relax physically and mentally. Mental pressure is a key attention. If people cannot relax mentally and physically from boring work, they will have psychological imbalance issues which will bring about various mental illness if life pressure and mental burdens accumulate for a long time. Community is the basic social management mechanism. Setting up city community leisure fitness projects within community is to promote people to apply healthy life style and get out home to use social and sports activities to cheer up and get relaxed so as to resist unhealthy mental problems. When they relieve physical pressure, they can relax from mental fatigue[2]. Secondly, pleasant feelings brought from sports activities can be indispensable. It is a satisfaction of physical relief. People can get utmost relaxation physically and mentally in city community leisure fitness activities. On the basis of freely choosing interactive projects, they can select activities according to their practical demands so as to realize the 1 mental liberation in the process of body-buiding.

\section{Types of city community leisure fitness service}

During the process of carrying out city community leisure fitness, keep serving the public as the basic principle. It is divided into the compatible operation style and exclusive operation style. The former mainly use center service to provide necessary health caring and medical support for the community, also equipped with the projects for shopping and education training and comprehensive cultural activities in practical activity center. For the community, compatible operational sports activity refer to the large-scale comprehensive community activity center within the community. The latter refers to the fitness activity center within the community specially providing sports service projects for community people. They mainly use comprehensive style or single project but the variety of the overall sports activity is close its own situation. In the comprehensive national fitness activity center, community management staffs can use various fitness activities to promote the citizens to carry out multi-level and comprehensive fitness activities so as to improve the internal leisure fitness environment.

\section{Perfection approaches of city community leisure fitness service projects}

As people's life style and consumption level changes, community leisure fitness service projects supported by government or self-run fitness places have gradually developed. But some problems existing in the development process are required to be solved urgently. 


\section{Optimize the management and control channel}

During the practical management process, the management staffs should establish relevant clause-government mechanism to optimize the government's management on community sports fitness service. Firstly, deepen the management fitness facilities. Local government should provide necessary financial subsidies but also should scientifically use tax-free mechanism, land transfer mechanism and low-price land renging and other political strategies to deepen government's support for communities with the practical demand as the basis to confirm the community development path. Also government should guarantee to provide the best service for the public and focus on community security management and risk management [3]. Secondly, deepen the sports community cooperation mechanism. In the operation process of practical projects, community management staffs should make innovative design on community activities to establish effective cooperative mechanism led by the civil administration organizations together with enterprise units. This can increase the actual operation funds of community but also can further promote the community activities. In the time of marketing economy, this is a win-win strategy. Besides, combined with sports association, establish feasible sports groups to stimulate citizens' passion for sports. Optimize and establish the overall upgrading of city community leisure fitness service project operation mechanism. Thirdly, the community can organize competitions and activities. Thus, management staffs should innovate the development path through organizing some competitive activities on the one hand to effectively mobilize community citizens' activity to truly achieve the harmonious development of people physically and mentally and construct the new fashion of community. On the other hand, carry out sports fitness knowledge consulting service for community citizens regularly to make sure they can master correct fitness knowledge and skills and to establish the trust between community and cities to truly realize the target the scientific body-building.

\section{Optimize and develop public fitness service resources}

During the process of building and perfecting city community leisure fitness service projects, the precondition of all activities is to optimize national fitness resources. Only by guaranteeing the completeness and order of resource structure can city community leisure fitness service project can truly satisfy the demand of the time. Management staffs should effectively allocate fitness resource structure and focus on establishing optimized guarantee measurement to improve the lifeline of public service projects and establish the most optimized handling mechanism based on specific problems. In the process of practical management, community management staffs should start from the target level for the control and supervision of public service resources with the resource development in the city community leisure fitness service projects as the basic target to intensify detailed resource reuse mechanism. Besides, management staffs should make centralized control on specific resource structures and pay attention to the completeness of principle structure. Principle projects are involved with the effective application of fitness resources, the aesthetic of environment construction, and the upgrading of citizens' concept of independent participation during the construction process and the high accessibility of fitness facilities [4]. Management staffs should make specific problem-solving strategies based on detailed problems. At last, the community principal should operate the most optimized measurements on city community leisure fitness service projects. Firstly, community management staffs should actively innovate the national leisure fitness patterns to promote the community to establish more optimized control and supervisory mechanism and use the optimized measurements to reform the fitness resource management system so as to improve the time particularity of community management structure. Secondly, community management staffs should use scientific methods to reasonably allocate the national fitness fundamental resources to establish national fitness resource protection mechanism to scientifically lay out the environment through constructing the most optimized operating structure for intensification of national fitness ecological protection. Management staffs should establish and construct the project handling strategies and create the humanity and cultural environment for national fitness. During deeply exploring the national fitness cultural service resources, further 
optimize and improve the activity of citizen to participate in national fitness service. Then community management staffs should use effective lectures and promotion to improve citizen's concept of consumptive fitness. At last, community management staffs should combines with local government to focus on speeding up the community transportation infrastructure construction and complete the communication facility construction. As city community leisure fitness service projects start not long, management staffs should focus on upgrading the satisfaction mechanism of fitness demands and use scientific control mechanism to focus on constructing a national public fitness service system during improving city community leisure fitness service projects. During the practical operation of control measurement implementation, community management staffs should fully combine with resource structure in different regions and establish the most effective city community public fitness resources not only for the purpose of realizing the maximization of supply quantity but also the optimization of resource supply so as to promote the positive development of community fitness service projects.

\section{Intensify service mechanism}

When constructing city community leisure fitness service projects, communities should focus on guarantee the community citizens to participate in fitness activity and legal right so as to set the target of intensifying people's physical quality and truly establish beneficial projects which can improve the life standard and quality of community citizens. Establishing optimized city community leisure fitness service projects can not only improve people's awareness on fitness activities but can also effectively maintain the harmony and stability of city community to make sure the community service projects are with basic public welfare and convenience[5]. During constructing specific project service system, truly realize the actual value of people-benefit project of public infrastructure facilities. If optimized development of Chinese city community leisure fitness service project can be achieved, China should intensify the system service concept when enriching the quality of public infrastructure to make sure that community internal fitness service structure can truly accord with citizens' demands. Besides, inner community can open specific fitness places to promote the diversified development of service structure and forms to guarantee the diversified development of community entertainment activities. Management staffs should establish specific management mechanism based on detailed issues so as to make sure the comprehensiveness of community can be improved during the development of city community leisure fitness service projects.

\section{Conclusion}

To sum up, during the process of perfecting Chinese city community leisure fitness service projects, community management staffs should join hands with local government to establish and perfect control and supervisory mechanism and operation measurements to realize the target of changing modern people's life style with the reasonable allocation of leisure fitness resource as the measurements to intensify the effect of overall community activities. In city life, only to make sure the physical and mental health of citizens can better implement scientific development concept to promote the harmonious development of the society and achieve positive cycle of social communication, life and work. Therefore, we should optimize control and regulation and perfect Chinese city community leisure fitness service projects and to promote cultural sustainable development for the purpose of realize the sustainable development of city community fitness service work.

\section{References}

[1] Chen Xiaohu. Main problems and development trend of city community leisure sports in pre-leisure time, Contemporary Sports Technology,2013,3(01):85-86. 
[2] Wang Zhankun. Study on the current situation of empty-nest elderly participation in sports in Zhejiang urban communities during the healthy aging development, Journal of Harbin Institute of Physical Education,2013,31(03):20-24.

[3] Liu Zhengjun, Pu Yonghui. Study on Shenyang public fitness industry- research on positioning strategy of small-size community fitness clubs, Proceedings of the Third Shenyang scientific academic annual conference .2016:671-675.

[4] Jiang Xufeng, Yuan Mengqian. Community transmission and construction of countryside community cultural construction, Social Sciences in Nanjing,2013,18(01):54-62,70.

[5] Qiao Dexu, Li Jian, Zhao Yongyan. Usage and management survey on "national fitness path" of community sports on Ha'erbin city, Proceedings of the 16th World mass sports conference.2013:1-1. 